\title{
Exploring the Application of Augmented Reality Technology in Early Childhood Classroom in Malaysia
}

\author{
Rasslenda-Rass Rasalingam ${ }^{1}$, Balakrishnan Muniandy ${ }^{2}$, Rasslene Rass \\ Rasalingam ${ }^{3}$ \\ ${ }^{123}$ (Centre for Instructional Technology and Multimedia, Universiti Sains Malaysia, Malaysia)
}

\begin{abstract}
The purpose of this study is to observe the familiarity of the AR application especially its implementation in a learning environment, and to determine the effectiveness of AR application in the classroom. The use of Augmented Reality (AR) in the classroom has the potential to enhance the traditional learning method. This study uses AR technology to implement an AR-learning environment for preschool children. Although previous studies have indicated that the AR technology enhances learning effectiveness, some other issues may cause negative effects. Therefore, this study is carried out to measure preschool children's motivational level and engagement after implementing this technology in the classroom. Results suggest that the AR technology is effective in maintaining a high level of motivation and engagement among preschool children.
\end{abstract}

Keywords: Augmented Reality, early childhood education, education technology, preschool children.

\section{Introduction}

The Augmented Reality (AR) is a technology that allows computer-generated virtual imagery information to be overlaid onto a live direct or indirect real-world environment in real time (Azuma 1997; Feng et al. 2008). It blurs the line between virtual and real time environment by enhancing what we see, hear, feel and smell. According to Ronald Azuma (1997) in his Survey of Augmented Reality paper found that it combines the real and the virtual, it's interactive in real-time and that it must register in 3D. Augmented really also adds graphics, sound, animation to the natural world as it exists. It also changes the way we view the world. The goal of augmented reality itself is to add information to a real object.

\section{How does AR improves performance in teaching and learning?}

Augmented reality is one way to bring experiential and location-based learning for students by supplementing existing worlds rather that creating new ones. Nevertheless, the use of the AR application on tablets and mobile phones may permit a rapid evolution of augmented reality technology. By combining technology familiar to students with locations that students see as their own, augmented reality has the potential to move learning out of the classrooms and into the spaces where students live. Encouraging informal learning that is easily accessible may prove particularly effective in engaging students, extending learning to spaces that might help them form connections with content, the locations that provide the context for it, and the peers that they share it with.

Modern classrooms are frequently enhanced through the addition of new technologies such as multitouch technologies. By using augmented reality technology in teaching and learning, users will actively involve in an experience. Therefore, they will retain and remember most of the information that is presented to them. Several research has shown that learning does occur in virtual environments and one of the earliest work in this area of applying AR to an educational context is the "Classroom of the Future", which conceptualizes how it could be possible to enhance interaction between instructor and student by employing AR technologies.

According to H. Lee and Lee (2008), if educational fields and AR technologies are brought together, learners can experience and learn while having fun. This can maximize the educational effectiveness. They developed a mathematical educational game. It supports that this educational game increases the enjoyment of the learner and the educational effect, but the reliability requires improvement.

Kirner and Zorzal (2005), developed an English letter spelling game. This game is designed in a way that the players have to pick up the right cards to spell the correct word in the game. If their spelling is correct, then a virtual object of the English letter card will appear on the monitor. By learning in such an attractive situation, it supports that this game allows players to interact more actively and fortify their ability of solving problems. Therefore, this technology could increase their performance in learning English vocabulary.

Augmented reality systems can improve performance when the training is conducted on real object (Boud et al. 1999). It supports that the implementation of this interesting material to the learning system can improve children's performance in teaching and learning. However, according to Shelton (2002) AR has not been much adopted into academic setting due to financial support and lack of awareness of needs for AR in 
academic setting.

\section{Augmented reality and preschool children}

These days, augmented reality is popping up in all sorts of places. This research is aimed at children in preschool to help them engage with the content and learn faster. It's a very smart concept because children learn by imagination. They learn by experience and by doing. They are more independent than toddlers (Howes and Rubenstein 1985). But, fear is often developed during the preschool years. This fear includes the new environment that they need to get use to in kindergarten. The separation from parents and other important people might affect the children.

An example of application that is used in preschool classroom is the Augmented Reality Children Storybook (ARCS) by Parhizkar et al. (2011). ARCS is targeted at young learners aged from 4 to 12 . This application is developed in a fun and engaging way in order to give them more motivation to learn. However, according to Parhizkar et al. (2011), every child has different learning skills and level. Therefore the application should be produced in various stories and element.

\section{Problem Statement}

With the advancement in technology today, children find that learning in traditional ways are dull and boring since there are so many entertainment alternatives out there which are more interesting then learning (Parhizkar et al. 2011). Not only that, preschool children have difficulties attending classes. They feel that preschools are boring and there is less entertainment in preschool compared to their homes. Having said that, preschools have also come out with some ideas to get these children to participate in activities, storytelling, and dramas (Jones and Reynolds 1992). Teachers too feel that children learn faster if they can interact with the object or even play a role in a story or situation presented to them. They are also trying to come out with other innovative ideas which will attract the children's attention or interest in order to make their learning sessions more interesting, fruitful and full of fun in order to encourage the learning process.

According to the Department of Statistics in Malaysia, in 2007, Malaysia had a total of 8.86 million children at the age group between 0-14 years old. A total of 15,195 children has difficulty learning to read and write. This is because children who do not read at a young age tend to have difficulty to develop their vital language skills. Therefore, it is very important to create an engaging environment to encourage them to learn. Children are naturally curious and playful. They learn when they explore and play, manipulate a wide range of real objects and get to see the results of their actions immediately (Berk, 2010).

According to Vygotski and Cole (1978), the way children learn is by internalizing the activities, habits, vocabulary and ideas of the members of the community in which they grow up. In other words, children learn best through primarily a social activity and participant in the social life of the school. Researchers also believe that the earlier a child start receiving education, the faster the child can absorb more knowledge.

\section{Purpose Of The Study}

The focus of this research was to evaluate the effectiveness of using AR technology in a pre-service classroom. According to Pengcheng et al. (2011), AR technology is an effective tool that integrates the real learning world with the virtual world created by computer software.

This research aims at studying the effectiveness of using augmented reality technology in early childhood education. Besides that, by using learning resources that is partly virtual and factual could increase the participation of the children in learning. They become more relaxed and the learning process becomes more engaging and interesting. Augmented Reality technology in a particular classroom helps children to be more engaged with the content and they tend to learn more rapidly.

\section{Research Question}

1. How do preschool children react to the use of augmented reality technology for the first time in classroom?

2. What role does augmented reality play in the process of learning among preschool children?

3. How are the experiences of preschool children when using augmented reality?

4. How does augmented reality increase the motivation and engagement of learning?

\subsection{Learning Theories}

\section{Theoretical Framework}

Technologies could be helpful in classroom settings by encouraging inquiry, helping communication, constructing teaching products and assisting student's self-expression (Bruce and Levin 2001). AR technology also could help teachers in building socially constructed student-centered learning. Past researchers have emphasized that technologies should be used in classroom settings (Solvie and Kloek 2007). In this research, the constructivism learning theory is used as a guide. 


\subsection{Constructivism Learning Theory}

According to Wertsch (1997), social constructivism not only acknowledges the uniqueness and complexity of the learner, but actually encourages, utilizes and rewards the integral part of the learning process. This research shows the effectiveness of AR technology by using constructivist learning which is self-directed, creative and innovative. It is in line with the purpose of this study to create a more relaxed, creative and innovative environment for teaching and learning to create new knowledge. By providing an innovative and engaging environment for learning, the preschool children could gain confidence and motivation by experiencing the task.

In this research, the researchers use the AR technology to construct meanings and enhance preschool childrens' understanding, as they respond and give positive feedback. Research has shown that the learning does occur in a virtual environment (Harrington 2006). The 3D animal that pops up on the flashcards in real time environment, allows the children to experience the learning process in $3 \mathrm{D}$.

\subsection{Vygotsky's Social Cultural Theory}

According to Vygotsky (1978), children, especially preschoolers, often speak to themselves as they are trying to understand something. This self-talk helps them to work things out in their own minds. In this research, the preschool children often repeat the name of the particular animal when they experience learning in 3D. Vygotsky (1978) believes that this "private speech" lessens with age until it becomes non-existent.

Vygotsky believed that learning begins at birth and continues throughout all of life. One of the most important ways that advancements in development are achieved is through what Vygotsky called "the zone of proximal development (ZPD). Vygotsky's (1987) "zone of proximal development", states that learners are challenged within close proximity to, slightly above their current level of development. In this research, the preschoolers gain confidence and motivation by experiencing the tasks. Teachers and other educators who wish to utilize the benefits of ZPD often employ scaffolding in classroom. Figure 1, shows the scaffolding process of AR technology in a preschool classroom.

Figure 1 - Scaffolding AR technology in a preschool classroom

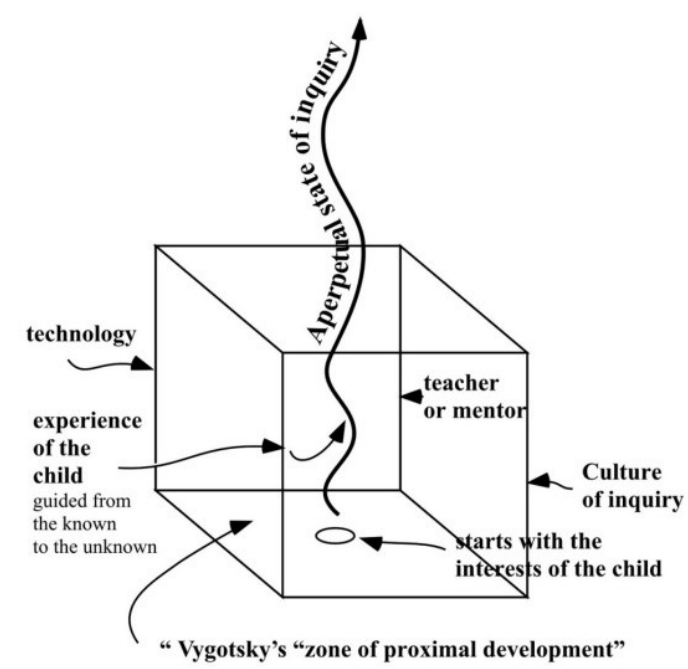

The technology tools that were used in this research is the AR technology. The role of AR technology in this research is to support the preschooler's development by providing structure to get them to the next level. As the preschooler's ability in storing the information increases, they are able to master the concept independently. This technology helps the preschool children to communicate and scaffold the content while engaging them with information. AR application in this research provides a direction in order to help the child focus on the learning and help them remember and store those information in their memory.

\section{Findings}

Results from the qualitative data analyses for the four research questions are presented according to the following themes: (1) children's' reaction when using AR for the first time, (2) the role of AR in the process of learning, (3) children's experiences using AR, (4) motivation and engagement of learning when using AR. As described above, the followings are the findings of this study: 


\subsection{Preschool children's reactions to the use of AR}

Preschool children's reaction to the use of AR was essentially measured by observation and video recordings' analysis. Based on the observation, the result shows that the use of AR in preschool education supported that it can be a key component in the learning environment of the future. This technology showed that it has the potential to support teaching and learning with the groups of young children in the classroom. Through observation, it's shows that this method of teaching is so much different than the traditional way of teaching. Kids responded to gadgets, in this case the Apple IPad which has become a fascination among people nowadays.

They seemed excited about this whole idea of learning using the gadgets rather than normal blackboards. They reacted to the projected image of a particular 3D animal that pops up when they hold the flashcard in their hand. Generally they were very excited as soon as the 3D objects pop-up on the IPad screen. A boy jumped and screamed at one of his friends.

$$
\begin{gathered}
\text { "Wow, I see something on the card. This is cool. I want to try all of the cards" } \\
\text { Alif, 6-year old preschooler }
\end{gathered}
$$

Alif was so excited when he was first introduced to the AR application. Based on the observation, when the researcher entered the classroom, Alif prefers to sit alone and doesn't want to join with other children. But as soon as the researcher introduced the application of learning animals using AR technology, he became excited and curious about the lesson.

A few children didn't believe that the 3D objects can pop-up on the screen. Some of them even question whether we are doing magic. They really enjoy it. It can be seen through their facial expressions. They were so happy. They look the flashcards and tried it themselves and they were amazed that the $3 \mathrm{D}$ objects can pop-up on screen. And they also respond well when they tap any of the animals and are able to listen to the name of that particular animal. This process helped them to remember it in their long-term memory.

The preschoolers tended to show interest and they become more sociable in learning and in acquiring new knowledge. The observation had made the children to mingle and take part in the learning process. They are definitely more interested and willing to participate during the research. Most importantly, the children's overall reaction to the AR application was very positive. When the researcher ended the lesson, a 6 -year old preschool child, Anis said:

"Can we do it once more? Miss, can we use this in class? I want to learn using this. Miss, please come again tomorrow."

The children were so sad and depressed when the researcher ended the lesson. They were hoping that the researcher will continue the lesson. The feedback from the children shows that this technology could motivate children to learn.

\subsection{The role of AR technology in the process of learning among preschool children}

The role of AR in this case is without doubt is to capture their attention. Feeding them with information will not prepare them for the future but also to teach them on how to visualize and use media to nurture children's natural curiosity and inspire them to explore the world around them. At the point when they were first introduced to the AR flashcards, the children gave their full attentiveness. This shows that AR has managed to capture their attention. This is because most of them think that academic subjects are abstract and have nothing to do with the world around them. But based on this research, it shows that the use of flashcards could enhance active learning and this is definitely a total divergence to traditional teaching method.

Learning tends to be more effective, efficient, and dynamic if it's conducted in a more educative environment where technology is easily accessible for the children. Whether at classroom or at home, teachers and parents should act as a team in making sure that there are no disturbances, for example loud noises, when they are being taught. Basically this is a two way of communication which helped to develop the children's understanding and to enhance their memory. Access to the right kind of information lead to forming of a foundation that provides the students the tools they needed to be able to learn faster and more efficiently. In short providing a better understanding could enhance learning experiences. Figure 2 shows the preschool children interacting with the AR application. 
Figure 2 - Preschool children interacting with the AR application

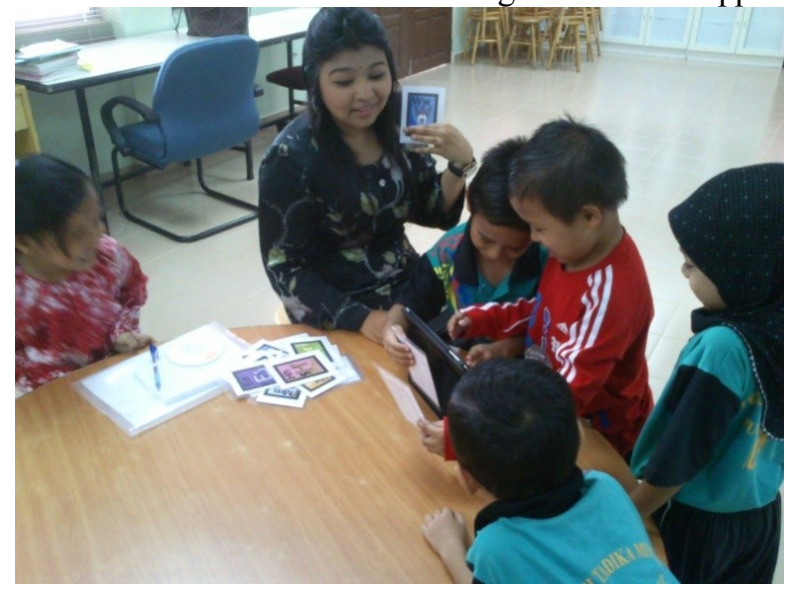

\subsection{Preschool children's experiences using AR technology}

AR helps to build a learning experience for the child that takes place across platforms, all with the goal of accelerating learning. There were truly engaged with the virtual 3D animals. This was based on the interview that took place at the end of the session.

When Siti, a 6-year old preschooler and an IPad user, was asked about her experience using AR technology in classroom, all she said was:

"The class was nice. I see animals on the cards. I love to learn this way. I have IPad at home but I only play games with the IPad...... I play the Angry Bird game and car racing games. I like to learn this way because there is animal on the card when I bring the cards near to the camera. Yes, easy to learn this way. I had fun today. I want to use this in class. "

Based on the interview, Siti prefers to learn using AR technology in classroom rather than the traditional way. According to her, the animals that appears on the flashcards looks real and she was so excited learning by using this technology. When asked about the alphabets at the end of the class, she responded well and gave excellent feedback. This shows that most children able to remember and retain the information and the subjects that were taught using the AR application. It enables them to acquire new knowledge rather than wasting their time playing games all day long.

Based on another interview with Adi, who is also an iPad user said that he only plays games on the IPad and he did mention that he doesn't know that the IPad can be used for learning purposes.

"My dad has IPad. I only play games on the IPad...I have so many games. Racing games, Angry Bird game, Talking Tom. I don't know we can use IPad to learn ABC. I love to learn this way. Can I learn this at home?"

Based on another interview with a 6 year-old preschooler, he did mention that animation will be better. By adding animation of 3D animal, this could increase the level of excitement among the preschool children. Figure 3, shows preschool children responding to gadgets.

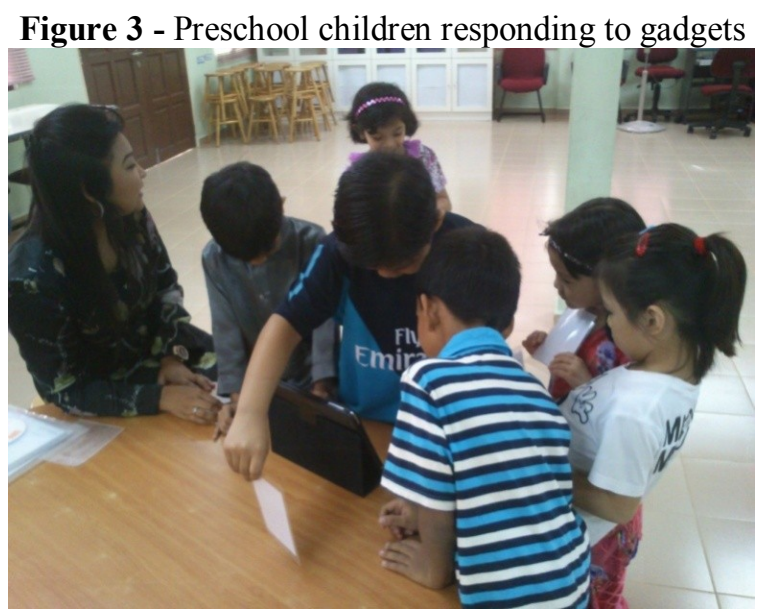

"The cards are nice. When I bring the cards to the camera, there is animal. But the animals are not moving...I want the animals to move"

Naim, 6-year old preschooler 


\subsection{Motivation and engagement of learning when using AR}

Motivation was essentially measured by participant observation, video recording and unstructured interviewing by asking open-ended questions to the children. As a baseline, the researcher studied the children's interactions while using the augmented reality application and the researcher observed that most of the children were active. While one of the child was called to test the application, the others were excited and came near to view the $3 \mathrm{D}$ animal that appeared on the flashcard. This shows that the augmented reality technology encourages and gives motivation to the children to learn.

Based on the observation, children are found to be motivated to learn. When the researcher first demonstrated the application, the children were so interested and they move forward to see how the application works. Their positive attitude towards the AR flashcard application shows that they want to learn more about it.

Besides that, motivation and engagement was also evident at the end of the session, when most of the children chose not to return to their class, but rather remain at the computer lab to play with the augmented reality flashcards. Finally, motivation levels were high because children never gave up using the application although they respondent the wrong answer at the beginning. This shows that, even when feedback showed that they were very wrong, nobody quit flashing the flashcards until they finished the 26 alphabets and managed to identify all of the animals correctly. Curiosity has also been another factor contributing to motivation. They were so curious while flashing the flashcards and suddenly the 3D animals appeared out of nowhere in Figure 4.

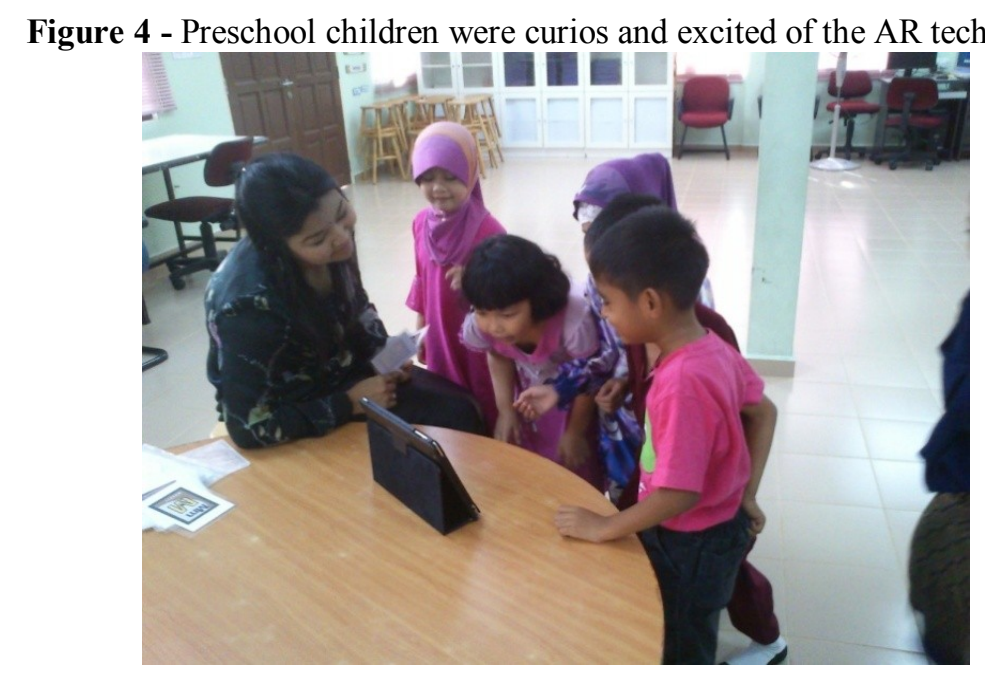

VII. Discussion

The findings and results, shows that childrens are responding well to the AR technology. This technology enhances childrens' motivational level, information and experiences that the children will never forget, e.g. they keep on repeating the animal name that they saw on the flashcard until end of the session. This may lead to an intrinsic motivation to learn. The application manage to grab their attention and interest, therefore the engagement level increases. Students motivation "refers to a student's willingness, need, desire and compulsion to participate in, and be successful in, the learning process" (Bomia et al., 1997, p.1). According to Peterson et al. (2007), when technology integration is used correctly, it can improve students' motivation. Curiosity was one of the positive feedbacks as well. They waited and finished all of the 26 flashcards that shows all of the 3D animals. In terms of maintaining motivation, this was a crucial factor as well.

The development of this interactive technology is valuable in its potential to enhance the traditional method of learning. Besides that, AR applications in education setting are attractive and exciting for student (K. Lee 2012). The integration of the AR technology has dramatically increased the efficiency and effectiveness in learning. By implementing this technology in preschool classroom, children become excited and engaged in the experience. They remember and retain the most of the information that was presented to them. They also had a lot of fun using this technology to learn in classroom.

Some of the children did mention that if there is an element of animation, the learning process will be more engaging and exciting. This is because they get frustrated when they could only see the animal, not the movement of that animal. Since children lose their focus of their attention frequently, it may be boring just to see a static 3D animal appearing on the flashcard. Therefore, if animation elements are included, the outcome would be better and more effective so that the particular 3D object will look more real. Future work should consist of adding the animation features. This can positively influence the effectiveness of using AR technology in classroom. 


\section{Recommendations}

The research in this article supported the use of augmented reality in a preschool classroom. The use of this technology was beneficial both to the educators and the preschool children. Therefore, the AR technology should be implemented in preschools to motivate the children to learn. Besides that, this technology provides an engaging environment for learning.

The experience of conducting research on the effectiveness of the AR technology for learning presents positive suggestions for future research as well. After implementing this technology in a preschool classroom, the researcher found out that if some of the features of the $3 \mathrm{D}$ object such as adding on animation of the particular animal, the results may have been different. Therefore, future researcher should consider the element of animation while developing an AR application as well as investigating other features and design issues that could positively influence the effectiveness of this technology in early childhood education. Besides that, the AR flashcards can also be extended to other subjects such as learning number, colors, alphabets, etc. Additionally, further research into the disadvantages of AR technology may also be carried out in determining the best qualities of teaching and learning in early childhood education. The detailed experience of the researcher in this study should be considered as a guideline and prevent the pitfalls of AR as well as that which may befall future researchers.

\section{Conclusion}

AR technology is an effective tool that integrates real learning world with virtual world created by computer software. Preschool children can acquire much more knowledge and experience in learning by using this technology in classroom compared to the traditional method of learning in classroom. An augmented reality application called AR Flashcards was used to determine the effectiveness of AR technology in early childhood education. AR Flashcards is a simple low-cost application which was designed for the iOS applications. It allows simulation and interaction with 3D virtual animals generated on a marker. Results showed that children are responding to gadgets and to the AR technology. They completed the scenario quite easily with interest and enjoyment. This technology has also increased their motivational level and engagement in learning.

The results indicated that the AR technology provided a fun and engaging environment. Therefore, it's an effective foundation to use AR technology as an educational tool. The task for educators and researchers now is to find an effective and a better combination of the AR technology and to make more excellent use of AR technology in early childhood education.

\section{References}

[1] Boud, A. C., Haniff, D. J., Baber, C., \& Steiner, S. J. Virtual reality and augmented reality as a training tool for assembly tasks. In Information Visualization, 1999. Proceedings. 1999 IEEE International Conference on, 1999 1999 (pp. 32-36). doi:10.1109/iv.1999.781532.

[2] Bruce, B. C., \& Levin, J. A. (2001). Roles for New Technologies in Language Arts: Inquiry, Communication, Construction, and Expression Mahwah, NJ: Lawrence Erlbaum Associates. [ISBN: 0-8058-4518-6] In James Flood, Diane Lapp, James R. Squire,\& Julie R. Jensen (Eds.) (2003), Handbook of research on teaching the English language arts).

[3] Clark, A., Dünser, A., \& Grasset, R. (2011). An Interactive Augmented Reality Coloring Book. Paper presented at the SIGGRAPH Asia 2011, Hong Kong, China, December 12 - 15, 2011.

[4] Freitas, R., \& Campos, P. (2008). SMART: A System of Augmented Reality for Teaching 2nd grade students. Paper presented at the Proceedings of the 22nd British HCI Group Annual Conference on People and Computers: Culture, Creativity, Interaction Volume 2, Liverpool, United Kingdom.

[5] Harrington, M. C. R. (2006). Situational learning in real and virtual space: lessons learned and future directions. Paper presented at the ACM SIGGRAPH 2006 Educators program, Boston, Massachusetts.

[6] Using Technology to Motivate Students to Learn Social Studies (2004). Contemporary Issues in Technology and Teacher Education. http://www.citejournal.org/vol4/iss1/socialstudies/article1.cfm.

[7] Howes, C., \& Rubenstein, J. (1985). Determinants of toddlers' experience in day care: Age of entry and quality of setting. Child care quarterly, 14(2), 140-151, doi:10.1007/bf01113407.

[8] Hsieh, M.-C., \& Lee, J.-S. (2008). AR Marker Capacity Increasing for Kindergarten English Learning. Proceedings of the International MultiConference of Engineers and Computer Scientists IMECS 2008 Hong Kong, Vol. I.

[9] Jones, E., \& Reynolds, G. (1992). The Play's the Thing: Teachers' Roles in Children's Play: Teachers College Press.

[10] Lee, H., \& Lee, J. (2008). Mathematical Education Game Based on Augmented Reality. In Z. Pan, X. Zhang, A. Rhalibi, W. Woo, \& Y. Li (Eds.), Technologies for E-Learning and Digital Entertainment (Vol. 5093, pp. 442-450, Lecture Notes in Computer Science): Springer Berlin Heidelberg.

[11] Lee, K. (2012). Augmented Reality in Education and Training. TechTrends, 56(2), 13-21, doi:10.1007/s11528-012-0559-3.

[12] Parhizkar, B., Shin, T. Y., Lashkari, A. H., \& Nian, Y. S. (2011). Augmented Reality Children Storybook (ARCS). International Conference on Future Information Technology (IPCSIT) 13 (IACSIT Press, Singapore.

[13] Pengcheng, F., Mingquan, Z., \& Xuesong, W. The significance and effectiveness of Augmented Reality in experimental education. In E -Business and E -Government (ICEE), 2011 International Conference on, 6-8 May 2011 2011 (pp. 1-4). doi:10.1109/icebeg.2011.5881654.

[14] Peterson, K., Bury, B., \& Middlestead, R. (2007). The Effect of Technology Integration on Student Motivation, Engagement and Interest.

[15] Schmuck, R. A. (1997). Practical Action Research for Change [microform] / Richard A. Schmuck (Vol. Accessed from http://nla.gov.au/nla.cat-vn5624074). [Washington D.C.] :: Distributed by ERIC Clearinghouse.

[16] Solvie, P., \& Kloek, M. (2007). Using Technology Tools to Engage Students with Multiple Learning Styles in a Constructivist 
Learning Environment. Contemporary Issues in Technology and Teacher Education, 7(2), 7-27.

[17] Tizard, B., \& Hughes, M. (2002). Young children learning. Oxford: Blackwell.

[18] Vate-U-Lan, P. Augmented Reality 3D pop-up children book: Instructional design for hybrid learning. In e-Learning in Industrial Electronics (ICELIE), 2011 5th IEEE International Conference on, 7-10 Nov. 2011 2011 (pp. 95-100). doi:10.1109/icelie.2011.6130033.

[19] Berk, L.E. (2010). Infants, Children, and Adolescents: Prentice Hall PTR.

[20] Vygotskiǐ, L. S., \& COLE, M. E. (1978). Mind in Society: The Development of Higher Psychological Processes: Academic Press.

[21] Azuma, R. T. (1997). A survey of augmented reality. Presence: Teleoperators and Virtual Environments 6, 4 (August 1997), 355385. Cambridge,MA: The MIT Press.

[22] Feng, Z., Duh, H. B. L., \& Billinghurst, M. Trends in augmented reality tracking, interaction and display: A review of ten years of ISMAR. In Mixed and Augmented Reality, 2008. ISMAR 2008. 7th IEEE/ACM International Symposium on, 15-18 Sept. 2008 (pp. 193-202). doi:10.1109/ismar.2008.4637362.

[23] Kirner, C. \& Zorzal, E.R. (2005). Educational applications of augmented reality collaborative environments. Proceedings of sixteenth Brazilian Symposium on Informatics in Education, 114-124.

[24] Shelton, B. E. (2002). Augmented reality and education: Current projects and the potential for classroom learning. New Horizons for Learning. Retrieved from http://www.newhorizons.org/strategies/technology/shelton.htm.

[25] Chien-Hsu Chen, Chun Chin Su, Po-Yen Lee \& Fong-Gong Wu. (2007). Augmented Interface for Children Chinese Learning. Department of Industrial Design, National Cheng-Kung University, Taiwan.

[26] Wertsch, J.V (1997). Vygotsky and the formation of the mind. Cambridge.

[27] Bomia, L., Beluzo, L., Demeester, D., Elander, K., Johnson, M., \& Sheldon, B. (1997). The impact of teaching strategies on intrinsic motivation. Champaign, IL: ERIC Clearinghouse on Elementary and Early Childhood Education. (ERIC Document Reproduction Service No. ED 418 925).

[28] Guba, E. G., \& Lincoln, Y. S. (1994) Competing paradigms in qualitative research. In N. K. Denzin \& Y.S. Lincoln (Eds.), Handbook of qualitative research (pp. 105-117). Thousand Oaks, CA: Sage.

[29] G. Burdea and P. Coiffet. (2003) Virtual reality technology (2nd ed.), New York: John Wiley \& Sons.

[30] Marshall, C., \& Rossman, G.B. (2006). Designing qualitative research (4th Ed.) Thousand Oaks, CA: Sage.

[31] Natasha Mack, Cynthia Woodsong, Kathleen M.Macqueen, Greg Guest \& Emily Namey. (2005) Qualitative Research Method: A Data Collector's Field Guide (pp.20). 